\title{
ENTREVISTA COM O MÉDICO GINECOLOGISTA GERSON LOPES
}

\author{
por Lina Wainberg
}

Gerson Lopes - Médico pela Faculdade de Medicina da Universidade Federal de Juiz de Fora/MG; especialista em Ginecologia e Obstetrícia e ginecologista com atuação em Sexologia, ambos pela Federação Brasileira das Associações de Ginecologia e Obstetrícia (Febrasgo); Membro Honorário da Sociedade Brasileira de Urologia (SBU); Membro da Comissão Nacional de Sexologia da Febrasgo; Professor do Curso de Pós-Graduação em Sexologia Clínica pela Faculdade Bahiana de Medicina e Saúde Pública/CESEX; Fundador do Instituto de Saúde Sexual/Educação Continuada (ISSEDUCA); Membro da International Society for Sexual Medicine (ISSM), da Sociedad Latino-Americana para el Estudio de la Impotencia y la Sexualidad (SLAMS); Membro da Academia Internacional de Sexologia Médica (AISM) e Coordenador do Departamento de Medicina Sexual do Hospital Mater Dei/BH/MG.

\section{Como a ginecologia brasileira tem avançado nos es- tudos da sexualidade?}

Atualmente temos, em quase todo o país, muitos ginecologistas com "atuação em sexologia" com excelente formação e creditação, em que alguns, inclusive, têm estudos reconhecidos não só no Brasil, mas internacionalmente. Isso tudo, a meu ver, se deve a liderança de um ginecologista, Ricardo Cavalcanti, quando há anos junto com outros colegas criaram a Comissão Nacional de Sexologia (CNS) da Federação Brasileira das Associações de Ginecologia e Obstetrícia (Febrasgo). Seus eventos nacionais na época, fizeram um sucesso estrondoso, durante bons anos, com a participação de diferentes especialistas que atuavam na área, seja médica, psicológica, educativa e social (jornalistas etc.).

\section{É importante que o ginecologista aborde o tema da} sexualidade nas consultas de rotina? $\mathrm{Na}$ sua visão, por que muitos profissionais não o fazem?

Não diria que seja apenas importante, acredito ser fundamental no momento em que a abordagem médica exige de todos esses profissionais um compromisso com a qualidade de vida de quem ele propõe ajudar. E sexualidade segura e prazerosa é hoje considerada como um dos indicadores de qualidade de vida de uma população, segundo a OMS. Há vários estudos que mostram que se o ginecologista colocasse apenas duas perguntas em todas as suas consultas - "Você tem vida sexual ativa?" e "Você tem alguma dificuldade sexual que te incomoda?" - a possibilidade do surgimento de queixas sexuais aumentaria de cinco a seis vezes, comparando ao eclodir espontâneo da queixa. Infelizmente, a maioria não aborda a sexualidade em suas consultas de rotina por uma série de "medos": perda de autoridade, problemas com o tempo de consulta, falta de (in)formação adequada da função sexual e sexualidade. Jean Claude Nahoum, ginecologista e filósofo, além de ser também um dos principais responsáveis pela formação da CNS da Febrasgo junto com Ricardo Cavalcanti, disse de maneira sábia certa vez que "o ginecologista não pergunta sobre sexualidade às pacientes por não saber o que responder".

Quais as habilidades que um ginecologista deveria desenvolver para o manejo das queixas sexuais de suas pacientes?

Pela sua formação muito tecnicista o ginecologista necessita desenvolver algumas habilidades (nem sempre fáceis a ele) como bem coloca a pergunta, ao se propor abordar a queixa sexual de suas pacientes. Destacaria a empatia, a congruência, a aceitação incondicional do outro, o "ler nas entrelinhas" (traduzir mensagens manifestas em latentes), o respeito pleno à paciente/casal e aqui estenderia ao horário, o não atendimento de telefone enquanto está na consulta, a confidencialidade (portanto, garantia total de ausência da atendente de sala, boa acústica com impedimento de vazamentos de som e ruídos), o respeito profundo à sexualidade do outro/casal sem se assustar com a queixa e suspender julgamentos. E deixar de apenas ver a paciente (basta não ter problema de visão), mas também observá-la (envolve o psíquico), bem como passar a escutá-la (envolve o psíquico para ter uma escuta melhor) e não só ouvi-la (bastaria ter um sistema auditivo sem problema). Em uma única palavra: ACOLHIMENTO. 
Até onde o ginecologista pode ir? Ele está preparado para um trabalho multidisciplinar?

Nos casos de disfunções sexuais cuja etiologia é orgânica ou psicológica por ignorância (desconhecimento), mitificação e falhas simples de comunicação, eu acho que há espaço para ajuda de um ginecologista que tenha as habilidades já citadas, porém devem ser encaminhadas para outros profissionais casos de maior complexidade que envolvem fatores psicológicos mais profundos e aqueles ligados à dinâmica relacional. Infelizmente, muitos ginecologistas ainda não estão atentos que em sexualidade o trabalho multidisciplinar é imperioso, contando com a ajuda de psicólogos, psiquiatras, urologistas, fisioterapia etc.

\section{Qual dimensão que os laboratórios têm nas inter- venções em sexualidade?}

Ainda é pequena, pois a maioria das queixas sexuais têm origem nas questões psicossociais. Entretanto, não há como negar que o conhecimento maior da fisiologia do sistema nervoso central e periférico abre um espaço significativo para a farmacoterapia adjuvante, ou seja, medicamentos com possíveis ações pró-sexuais. Em um artigo escrito por mim sobre "O uso de medicamentos na sexualidade feminina",' conclui, na época, que "deve-se lembrar que o uso de medicações tem de seguir rigoroso critério científico e nenhuma droga tem o poder de fazer com que a pessoa se interesse pelo sexo ou fazer o parceiro interessante e interessado, quando existem problemas intra ou interpessoais importantes". Continuo a pensar do mesmo jeito, mesmo em época de testosterona, flibanserina e bremelanotide.

Você acredita que teremos mudanças significativas no comportamento sexual das pessoas, após a pandemia da covid-19?

Infelizmente não. Não percebo mudanças realmente significativas no sentido positivo nem durante a pandemia, pois já venho atendendo em consultório algum tempo. Talvez, no início dela sim, mas nos últimos meses vale a clássica expressão "voltou tudo como dantes no castelo de Abrantes". Em artigo recente (july 2020) publicamos junto com outros colegas na prestigiosa revista Archives of Sexual Behavior um artigo sobre "COVID-19 and Sexuality: Reinventing Intimacy"2 e não sei realmente se aqui as pessoas reinventaram as suas intimidades como esperávamos e se podemos esperar grandes mudanças no comportamento sexual delas pós pandemia baseado na solidariedade e companheirismo. Gostaria de acreditar, "mas não sei não”, como diria um mineiro desconfiado.

\section{Sabemos que você é um apaixonado por vinhos. Qual a relação com a sexualidade?}

Um hobby que tive que descobrir depois de alguns anos de terapia e que, por acaso ao passar na frente de uma livraria que tinha junto uma mistura de loja e wine bar, achei que poderia ser uma boa opção, pois já gostava muito de ler, e comecei a frequentar junto o mundo de Baco. E não parei mais. $O$ que têm em comum realmente vinho e sexualidade? O compromisso de ambos é com o prazer e alegria. O resto é balela. Abrindo um evento da Sociedade Latino Americana de Medicina Sexual com essa temática, em Buenos Aires, fui entrevistado por um jornalista, especializado em ciências de La Nación, que definiu bem o título da matéria: "Vino y sexualidad um dúo que excede la lógica de la ciência". Sempre me lembro de uma das poesias do grande poeta pantaneiro, Manoel de Barros:

A ciência pode classificar e nomear os órgãos de um/ Sabiá/ mas não pode medir seus encantos./ A ciência não pode calcular quantos cavalos de força/ existem/ nos encantos de um sabiá./ Quem acumula muita informação perde o condão de adivinhar: divinare./ Os sabiás divinam.

E é verdade, pois enquanto termino de responder as perguntas que me foram feitas, ouço um sabiá cantando na frente de meu prédio. Seu canto tem algo de divino como tem o degustar vinho, em que este é associado à dois deuses - Baco (Grego) e Dionísio (Roma). Imagine poder acrescentar aí Afrodite?

Lina Wainberg Psicóloga (PUCRS)

Especialista em Terapia de Casal e Família (INFAPA) Mestre em Sexologia (UGF)

Doutora em Psicologia (UFGRS) Diretora de Titulação SBRASH (desde 2014 até atualmente)
' LOPES, G. P. O uso de medicamentos na sexualidade feminina. RBM: Revista Brasileira de Medicina, Rio de Janeiro, v. 59, n. 9, p. 670-672, set. 2002.

2 LOPES, G. P. et al. COVID-19 and Sexuality: Reinventing Intimacy. Archives of Sexual Behavior, New York, v. 21, p. I-4, July 2020. Epub ahead of print. PMID: 32696 I54; PMCID: PMC7373209. Disponível em: $10.1007 /$ sI0508-020-01796-7. 